\title{
Secretoglobin Family 1D Member 2
}

National Cancer Institute

\section{Source}

National Cancer Institute. Secretoglobin Family 1D Member 2. NCI Thesaurus. Code

C113537.

Secretog lobin family 1D member 2 (90 aa, 10 kDa) is encoded by the human SCGB1D2 gene. This protein is involved in binding to androgens and other steroids. 